\title{
Influenza case definitions need to be fit for purpose
}

P Priest (patricia.priest@otago.ac.nz)1, H Kelly²

1. Department of Preventive and Social Medicine, Dunedin School of Medicine, University of Otago, New Zealand

2. National Centre for Epidemiology and Population Health, Australian National University, Canberra, Australia

Citation style for this article:

Priest P, Kelly H. Influenza case definitions need to be fit for purpose. Euro Surveill. 2015;20(25):pii=21162. Available online: http://www.eurosurveillance.org/

ViewArticle.aspx?Articleld $=21162$

Article submitted on 11 June 2015 / published on 25 June 2015

To the Editor: The recent paper by Jiang et al. [1] provides an in-depth analysis of the performance of different case definitions for detecting influenza $A\left(\mathrm{H}_{1} \mathrm{~N}_{1}\right)$ pdmog among adults in the community, including those who have not presented for medical attention.

The authors concluded that the revised World Health Organization (WHO) influenza-like illness (ILI) definition was an improvement on alternative definitions used by the United States Centers for Disease Control and Prevention (CDC) and the European Centre for Disease Prevention and Control (ECDC), based on its higher positive predictive value (PPV) and higher likelihood ratio for a positive test. However, these are not necessarily the most important measures of success for all ILI case definitions, and different definitions will be required for different purposes. Identify-ing influenza for surveillance, for case finding during activities to prevent spread during an epi-demic, and for case finding for participation in research studies of treatment or prevention of transmission will require different case definitions.

As the authors of the paper and accompanying editorial [2] note, important characteristics of a case definition for routine surveillance are sufficient sensitivity to identify the beginning of the influenza season or an epidemic, high specificity and consistent application over time. PPV is less relevant, because it varies with the prevalence of disease and the likelihood ratio is more rele-vant to clinical consultation rather than surveillance.

When almost complete case finding is required, for example, to detect a new strain as early as possible after it enters a country (it is probably not possible to keep out such strains $[3,4])$, highly sensitive case definitions are needed before laboratory testing, recognising that the PPV will be very low.

As noted by the authors, the key distinction between case definitions with higher and lower sensi-tivity is whether or not fever is required to meet the case definition. The WHO ILI case definition has poor sensitivity ( $36 \%$ for all reported episodes), as do all the other case definitions except acute respiratory illness (ARI), with sensitivity of $94 \%$. The next most sensitive case definition is the ECDC ILI definition (61\% for all episodes). The ARI and ECDC case definitions do not require fever. In the study by Jiang et al., only half of the 36 illness episodes presumed to be caused by influenza $A\left(\mathrm{H}_{1} \mathrm{~N}_{1}\right)$ pdmog were associated with fever. In addition to these 36 participants, a fur-ther 62 participants seroconverted but did not report episodes of illness and would not have been captured by any case definition (but may nonetheless shed virus [5]).

The findings from the recent study are consistent with published literature on the prevalence of fever and other symptoms in laboratory-confirmed cases of influenza. Among people with other respiratory symptoms and influenza $A\left(\mathrm{H}_{1} \mathrm{~N}_{1}\right)$ pdmog infection, reported fever prevalence can be as low as $38 \%$ for non-pregnant hospitalised adults with community-onset pneumonia or influenza-like symptoms and underlying conditions [6]. For other strains of influenza, as few as $26 \%$ of adults with respiratory symptoms have a fever (body temperature $\geq 37.8^{\circ} \mathrm{C}$ ) at presentation [7]. Where symptoms are not required for influenza testing (for example, when screening), the pro-portion of people with laboratory-confirmed influenza who have fever (body tempera-ture $\geq 37.8^{\circ} \mathrm{C}$ ) can be as low as $33 \%$ for influenza $A\left(\mathrm{H}_{1} \mathrm{~N}_{1}\right)$ pdmog [8] and even as low as $3 \%$ for other strains [9].

Studies that report symptoms in laboratory-confirmed cases of influenza generally report fever at the time of influenza testing and will underestimate the proportion with fever at some time during an illness episode. However, case definitions are applied by clinicians and public health staff when deciding whether to take a specimen for influenza testing, and whether to isolate or quarantine people. When a case definition includes fever, fever at presentation is thus critical for decisionmaking in practice.

No single case definition will satisfy all situations. For routine surveillance, we suggest that the ECDC case definition probably has the best balance of sensitivity and specificity. On the other hand, case definitions 
that do not include fever are necessary when finding almost all cases is required. Among those assessed by Jiang et al., only ARI has sufficiently high sensitivity for this purpose. Careful consideration is required to ensure that influenza or ILI case definitions are fit for purpose.

\section{Conflict of interest}

None declared.

\section{Authors' contributions}

The authors are equal contributors to all aspects of authorship.

\section{References}

1. Jiang L, Lee VJ, Lim WY, Chen MI, Chen Y, Tan L, et al. Performance of case definitions for influenza sur-veillance. Euro Surveill. 2015;20(22):21145. PMID:26062645

2. Penttinen P, Pebody R. Influenza case definitions - optimising sensitivity and specificity. Euro Surveill. 2015;20(22):21148. PMID:26062644

3. Kelly HA, Priest PC, Mercer GN, Dowse GK. We should not be complacent about our population-based public health response to the first influenza pandemic of the 21st century. BMC Public Health. 2011;11(1):78. http://dx.doi.org/10.1186/1471-2458-1178 PMID:21291568

4. Kelly HA, Mercer GN, Fielding JE, Dowse GK, Glass K, Carcione D, et al. Pandemic ( $\left.\mathrm{H}_{1} \mathrm{~N}_{1}\right) 2009$ influenza community transmission was established in one Australian state when the virus was first identified in North America. PLoS ONE. 2010;5(6):e11341. http://dx.doi.org/10.1371/journal. pone.0011341 PMID:20596536

5. Suess T, Remschmidt C, Schink SB, Schweiger B, Heider A, Milde J, et al. Comparison of shedding charac-teristics of seasonal influenza virus (sub)types and influenza $A\left(\mathrm{H}_{1} \mathrm{~N}_{1}\right)$ pdmo9; Germany, 2007-2011. PLoS ONE. 2012;7(12):e51653. http://dx.doi.org/10.1371/journal.pone.0051653 PMID:23240050

6. Gutiérrez-Cuadra M, González-Fernández JL, Rodríguez-Cundin P, Fariñas-Álvarez C, San Juan MV, Parra JA, et al. Clinical characteristics and outcome of patients with pandemic 2009 Influenza $\mathrm{A}\left(\mathrm{H}_{1} \mathrm{~N}_{1}\right) \mathrm{v}$ virus infec-tion admitted to hospitals with different levels of health-care. Rev Esp Quimioter. 2012;25(1):56-64. PMID:22488543

7. Louie JK, Hacker JK, Gonzales R, Mark J, Maselli JH, Yagi S, et al. Characterization of viral agents causing acute respiratory infection in a San Francisco University Medical Center Clinic during the influenza season. Clin Infect Dis. 2005;41(6):822-8 http://dx.doi.org/10.1086/43280o PMID:16107980

8. Li T, Liu Y, Di B, Wang M, Shen J, Zhang Y, et al. Epidemiological investigation of an outbreak of pandemic influenza $A\left(\mathrm{H}_{1} \mathrm{~N}_{1}\right)$ 2009 in a boarding school: serological analysis of 1570 cases. J Clin Virol. 2011;50(3):235-9. http://dx.doi.org/10.1016/j. jcv.2010.11.012 PMID:21195022

9. Priest PC, Jennings LC, Duncan AR, Brunton CR, Baker MG. Effectiveness of border screening for detect-ing influenza in arriving airline travelers. Am J Public Health. 2013;103(8):14128. http://dx.doi.org/10.2105/AJPH.2012.300761 PMID:23237174 